\title{
Does perioperative intravenous dextrose reduce postoperative nausea and vomiting? A systematic review and meta-analysis
}

This article was published in the following Dove Press journal:

Therapeutics and Clinical Risk Management

\author{
Seung Hyun Kim' \\ Do-Hyeong Kim² \\ Eungjin Kim' \\ Hyun Jung $\mathrm{Kim}^{3, *}$ \\ Yong Seon $\mathrm{Choi}^{2, *}$
}

'Department of Anesthesiology and Pain Medicine, Severance Hospital, Yonsei University College of Medicine, Seoul, Korea; ${ }^{2}$ Department of Anesthesiology and Pain Medicine, Anesthesia and Pain Research Institute, Severance Hospital, Yonsei University College of Medicine, Seoul, Korea; ${ }^{3}$ Department of Preventive Medicine, College of Medicine, Institute for Evidence-based Medicine, Korea University, Seoul, Korea

*These authors contributed equally to this work

Correspondence: Hyun Jung Kim Department of Preventive Medicine, College of Medicine, Institute for Evidence-based Medicine, Korea University, I26-I, Anam Dong, Seong

Buk Gu, Seoul 03722, Korea

Tel +82 22286 |34|

Fax +82 $22286 \quad$ I342

Email moole@korea.ac.kr

Yong Seon Choi

Department of Anesthesiology and Pain Medicine, Anesthesia and Pain Research Institute, Severance Hospital, Yonsei

University College of Medicine, 50-I

Yonsei-ro, Seodaemun-gu, Seoul 03722,

Korea

$\mathrm{Tel}+8222286|34|$

Fax $+8222286 \quad 1342$

Email moole@korea.ac.kr
Purpose: Perioperative dextrose-containing fluid administration has been used as a non-pharmacologic preventive measure against postoperative nausea and vomiting (PONV), a common and distressing complication of anesthesia. However, its efficacy remains unclear as previous studies reported inconsistent results. Our objective was to compare dextrose-containing fluid with non-dextrose-containing fluid in terms of PONV for 24 hours after surgery under general anesthesia. The effects of dextrose according to different types of surgery and the fluid volume were also examined.

Methods: We performed a systematic review and meta-analysis of randomized controlled trials (RCTs) comparing dextrose-containing fluid with non-dextrose-containing fluids after general anesthesia in terms of PONV incidence and the need for rescue anti-emetic therapies for 24 hours after surgery. A literature search was performed, using Medline, EMBASE, Cochrane Central Register of Controlled Trials, Web of Science, and Scopus, up to February 2018.

Results: We included seven RCTs. Compared with the control group, perioperative dextrose administration did not reduce the risk for PONV, with a relative risk (RR) of 0.72 (95\% CI: 0.50-1.03). However, perioperative dextrose reduced the requirement for anti-emetics, compared with the control group, with a RR of 0.60 (95\% CI: $0.44-0.83)$. The quality of evidence in this meta-analysis was poor due to high risks of selection and performance biases and substantial statistical heterogeneity. After subgroup analysis, the risk for PONV was reduced in patients who had undergone laparoscopic cholecystectomy, but not other surgeries, and the effects of dextrose on the risk for PONV did not differ according to the fluid volume administered.

Conclusion: Perioperative intravenous (i.v.) dextrose did not reduce the risk for PONV. However, it did reduce the need for anti-emetics after general anesthesia. Furthermore, the effects of dextrose varied according to the surgery type. Further studies are needed to determine the benefits of perioperative i.v. dextrose administration as a preventive measure against PONV.

Keywords: general anesthesia, PONV, dextrose, laparoscopic cholecystectomy

\section{Introduction}

Postoperative nausea and vomiting (PONV) is a common and distressing complication of surgery and anesthesia. Although these symptoms are usually self-limiting and non-fatal, they may cause problems, such as aspiration pneumonia, dehydration, prolonged hospitalization, wound dehiscence, water and electrolyte disturbances, and acid-base imbalances. ${ }^{1}$ From the patient's perspective, the experience of PONV may be worse than postoperative pain. ${ }^{2}$ Currently, many anti-emetic medications are used to prevent PONV. However, these relatively expensive drugs are associated with adverse effects, such as oversedation, hypotension, dry mouth, and dysphoria. ${ }^{3}$ Although 
non-pharmacological approaches, such as oral carbohydrate ${ }^{4,5}$ or fluid therapy have been attempted to minimize the cost and the potential side effects of the anti-emetics, there is limited evidence regarding adjuvant non-pharmacological therapies for PONV.

Gastric mucosal hypoperfusion consequent to hypovolemia, which can occur after prolonged fasting, may also be an important etiological factor for PONV. ${ }^{6}$ Intravenous (i.v.) fluid administration is known to reduce hypovolemia and hypoperfusion. Accordingly, many studies have evaluated whether the i.v. administration of dextrose-containing fluid can effectively prevent PONV via a mechanism potentially involving hyperglycemia. ${ }^{7,8}$ However, the ability of such fluid to prevent PONV remains controversial. Therefore, with this meta-analysis, we aimed to compare the efficacies of dextrose-containing fluid with other fluid for the prevention of PONV in multiple randomized controlled trials (RCTs).

\section{Methods}

Using multiple comprehensive databases, we sought literature comparing the effects of dextrose-containing fluid with non-dextrose-containing fluid on the incidence of PONV. This study was conducted according to the Cochrane Review Methods, ${ }^{9}$ and the PRISMA reporting guidelines.

\section{Data and literature sources}

We searched the Medline, EMBASE, Cochrane Central Register of Controlled Trials, Web of Science, and Scopus databases in February 2018. Initially, we used the following keywords and MeSH terms to search Medline: Postoperative Nausea and Vomiting, Glucose, Sodium Lactate, Anesthesia. Subsequently, these search strategies were adapted for other databases. No restrictions on publication language or year were applied. After the initial electronic search, we hand-searched further relevant articles from the identified studies. All identified articles were individually assessed for inclusion.

\section{Study selection}

Two reviewers (SHK and HJK) independently determined the inclusion of all studies according to the selection criteria. Two levels of screening were applied to the identified studies. At the first level, the titles and abstracts of the identified studies were screened. At the second level, the full text was reviewed. Studies were included in our meta-analysis if they met the following inclusion criteria: 1) a study population comprising adult patients undergoing surgery under general anesthesia;
2) an intervention of dextrose-containing fluid and control of fluid without dextrose; 3 ) outcome measures, including the incidence of PONV and need for rescue anti-emetic therapies; and 4) a prospective RCT design. Duplicate publications, review articles, and case reports were excluded.

\section{Data extraction}

The two reviewers (SHK and HJK) independently extracted data from each study using a predefined data extraction form. Any disagreement unresolved by discussion was submitted for review by a third author (YSC). The variables extracted were as follows: first author, publication year, baseline characteristics of patients, type of surgery, fluid intervention, and outcome results, including the incidence of PONV, incidence of vomiting, and number of patients requiring rescue anti-emetics.

\section{Assessment of methodological quality}

Two reviewers (SHK and HJK) independently assessed the methodological quality of each study using the Cochrane Collaboration tool for assessing the risk of bias. We assessed the following domains: random sequence generation, allocation concealment, blinding of participants and personnel, blinding of outcome assessment, incomplete outcome data, and selective reporting.

Publication bias was not assessable in these trials, as the tests for funnel plot asymmetry are generally only performed for a meta-analysis of at least 10 studies. Because our analysis included only seven studies, tests for asymmetry would be unable to differentiate chance from asymmetry and would thus be ineffective.

\section{GRADE assessment and summary of findings}

We used the Grading of Recommendations Assessment, Development, and Evaluation (GRADE) approach to assess the quality of the evidence associated with specific outcomes (incidence of PONV, postoperative vomiting, and requirement for anti-emetics) in our review and to construct a "summary of findings" table. The GRADE approach considers study risk of bias (methodological quality), directness of the evidence, heterogeneity of the data, precision of effect estimates, and risk of publication bias.

\section{Statistical analysis}

The primary outcome of our meta-analysis was the risk for PONV for 24 hours after surgery, while the secondary outcomes were the risk for postoperative vomiting and 
requirement for anti-emetic therapy for 24 hours after surgery. For dichotomous outcomes (incidences of PONV, postoperative vomiting, and anti-emetic requirements), the results are expressed as relative risks (RRs) with 95\% CIs. Data were pooled using a random-effects model, and the mean differences and 95\% CI are reported if continuous scales of measurement were used to assess the effects of treatment (postoperative glucose levels).

To estimate heterogeneity, we determined the proportion of between-study inconsistency attributable to true differences between studies (rather than differences attributable to random error or chance) using the $I^{2}$ statistic, wherein values of $25 \%, 50 \%$, and $75 \%$ are considered low, moderate, and high, respectively. Here, we conducted subgroup analyses of situations where type of heterogeneity might affect the results (type of surgery and volume of dextrose fluid). Three studies included patients undergoing laparoscopic cholecystectomy, three included patients undergoing gynecologic surgery, and one included patients undergoing gynecologic, urologic, or breast surgery. Accordingly, the type of surgery subgroups comprised laparoscopic cholecystectomy and gynecologic, urologic, or breast surgery. As all studies used 5\% glucose in the dextrose group, three subgroups were classified according to dextrose fluid volumes of $>1,000 \mathrm{~mL}, 500-1,000$, and $<500 \mathrm{~mL}$. All analyses were performed using RevMan version 5.2 (Cochrane Community, London, UK).

\section{Results}

\section{Identification of studies}

Our database searches yielded 8,138 articles. Of these, 583 publications were excluded as duplicates, and 7,477 were excluded because the title and abstract indicated that the studies did not fulfill the selection criteria. We obtained full manuscripts of the remaining 78 articles and, after a close review, identified seven relevant studies. Ultimately, seven studies ${ }^{10-16}$ were included in the review (Figure 1).

\section{Study characteristics and patient populations}

The seven studies had enrolled a total of 701 patients who underwent surgery under general anesthesia (Table 1). Of these, 347 patients had been assigned randomly to control groups; the remaining 354 patients had been assigned to dextrose intervention groups. The incidence of PONV was the primary outcome in six studies. Five studies included only female patients, while two included both male and female patients. Of the 49 male patients included in the analysis,

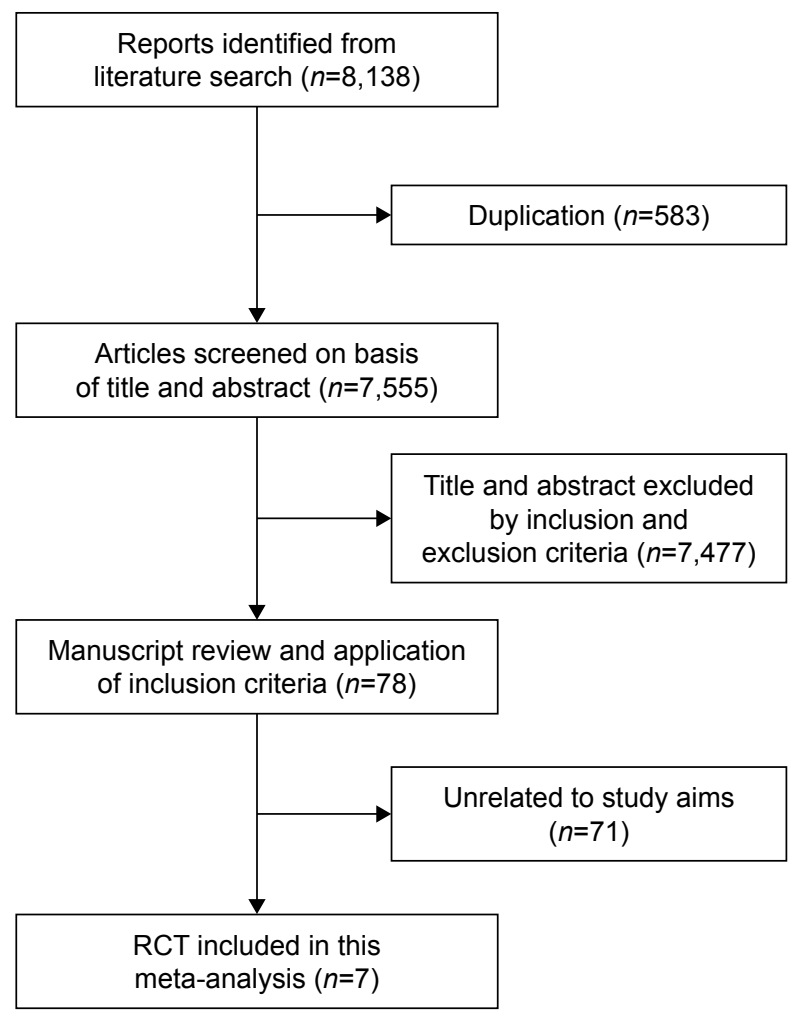

Figure I Meta-analysis flow chart.

Abbreviation: RCT, randomized controlled trial.

27 and 22 were included in the control and dextrose groups, respectively.

As noted previously, all patients in the dextrose group were administered a 5\% dextrose solution; patients in the control group were administered identical amounts of fluid without dextrose. In four studies, patients were administered $250-1,000 \mathrm{~mL}$ of fluid. In the remaining three studies, the amount of fluid was determined taking into consideration the body weight and duration of surgery. The timing of the intervention varied among the studies. The intervention was performed intraoperatively in three studies, ${ }^{10,13,14}$ postoperatively in three studies, ${ }^{11,15,16}$ and preoperatively in one study. ${ }^{12}$ Two studies each were performed in India, Iran, and the USA, while one study was performed in Ireland.

\section{Quality of the included studies}

The Cochrane Collaboration's risk of bias tool was used to assess the risk of bias in all included studies. The items assessed and recorded were as follows: random sequence generation (selection bias), allocation concealment (selection bias), blinding of participants and personnel (performance bias), blinding of outcome assessment (detection bias), incomplete outcome data (attrition bias), and selective reporting (reporting bias). The risks of biases were 
Table I The main characteristics of the studies included in the meta-analysis

\begin{tabular}{|c|c|c|c|c|c|c|c|}
\hline & $\begin{array}{l}\text { Number } \\
\text { (control, } \\
\text { dextrose) }\end{array}$ & $\begin{array}{l}\text { Incidence of } \\
\text { PONV (control, } \\
\text { dextrose) }\end{array}$ & $\begin{array}{l}\text { Population (ASA, } \\
\text { sex, age [control], } \\
\text { age [dextrose]) }\end{array}$ & $\begin{array}{l}\text { Type of } \\
\text { surgery }\end{array}$ & Control fluid & Dextrose fluid & $\begin{array}{l}\text { Timing of } \\
\text { intervention }\end{array}$ \\
\hline $\begin{array}{l}\text { Atashkhoei } \\
\text { et al }\left.\right|^{10}\end{array}$ & $\begin{array}{l}70 \\
(35,35)\end{array}$ & $16 / 35,8 / 35$ & $\begin{array}{l}\text { I, female, } \\
32.09( \pm I .02) \\
30.49( \pm 0.91)\end{array}$ & $\begin{array}{l}\text { Diagnostic } \\
\text { laparoscopy for } \\
\text { infertility }\end{array}$ & $\begin{array}{l}\text { Ringer's lactate } \\
714.7 \mathrm{~mL} \\
\left(10 \mathrm{~mL} \mathrm{~kg}^{-1} \mathrm{~h}^{-1}\right)\end{array}$ & $\begin{array}{l}5 \% \text { dextrose in } \\
\text { Ringer's lactate } \\
608.1 \mathrm{~mL} \\
\left(10 \mathrm{~mL} \mathrm{~kg}^{-1} \mathrm{~h}^{-1}\right)\end{array}$ & Intraoperatively \\
\hline $\begin{array}{l}\text { Dabu- } \\
\text { Bondoc } \\
\text { et al }{ }^{\prime \prime}\end{array}$ & $\begin{array}{l}62 \\
(32,30)\end{array}$ & $20 / 32,14 / 30$ & $\begin{array}{l}\text { I-2, female, } \\
37.5( \pm 9.8) \\
37.9( \pm 10.3)\end{array}$ & $\begin{array}{l}\text { Gynecologic, } \\
\text { laparoscopic and } \\
\text { hysteroscopic } \\
\text { procedures }\end{array}$ & $\begin{array}{l}\text { Ringer's lactate } \\
\text { I,000 mL }\end{array}$ & $\begin{array}{l}5 \% \text { dextrose in } \\
\text { Ringer's lactate } \\
1,000 \mathrm{~mL}\end{array}$ & $\begin{array}{l}\text { Immediately } \\
\text { after surgery } \\
\text { (in the PACU), } \\
>30 \text { minutes }\end{array}$ \\
\hline $\begin{array}{l}\text { Firouzian } \\
\text { et } \mathrm{al}^{12}\end{array}$ & $\begin{array}{l}121 \\
(60,61)\end{array}$ & NA & $\begin{array}{l}\text { I-2, female, } \\
41.44( \pm 12.75) \\
41.2( \pm 12.73)\end{array}$ & $\begin{array}{l}\text { Laparoscopic } \\
\text { cholecystectomy }\end{array}$ & $\begin{array}{l}\text { Ringer's lactate } \\
500 \mathrm{~mL}\end{array}$ & $\begin{array}{l}5 \% \text { dextrose in } \\
\text { Ringer's lactate } \\
500 \mathrm{~mL}\end{array}$ & $\begin{array}{l}30 \text { minutes before } \\
\text { induction of } \\
\text { anesthesia, } \\
>30 \text { minutes }\end{array}$ \\
\hline $\begin{array}{l}\text { McCaul } \\
\text { et al }{ }^{13}\end{array}$ & $\begin{array}{l}71 \\
(36,35)\end{array}$ & $6 / 36,10 / 35$ & $\begin{array}{l}\text { I, female, } \\
32.3( \pm 4.96) \\
33.2( \pm 4.9)\end{array}$ & $\begin{array}{l}\text { Elective } \\
\text { gynecological } \\
\text { laparoscopy }\end{array}$ & $\begin{array}{l}\text { Ringer's lactate } \\
\mathrm{I}, \mathrm{I} 15( \pm 363) \mathrm{mL} \\
\left(1.5 \mathrm{~mL} \mathrm{~kg}^{-1} \mathrm{~h}^{-1}\right. \\
\text { of fasting })\end{array}$ & $\begin{array}{l}5 \% \text { dextrose in } \\
\text { Ringer's lactate } \\
\mathrm{I}, \mathrm{I} 48( \pm 2 \mathrm{I}) \mathrm{mL} \\
\left(1.5 \mathrm{~mL} \mathrm{~kg} \mathrm{~kg}^{-1} \mathrm{~h}^{-1}\right. \\
\text { of fasting) }\end{array}$ & $\begin{array}{l}\text { After induction of } \\
\text { anesthesia, } \\
>20 \text { minutes }\end{array}$ \\
\hline $\begin{array}{l}\text { Mishra } \\
\text { et al }{ }^{14}\end{array}$ & $\begin{array}{l}100 \\
(50,50)\end{array}$ & $33 / 50,14 / 50$ & $\begin{array}{l}\mathrm{I}-2, \text { female and } \\
\text { male, } \\
39.6( \pm I 1.54) \\
37.42( \pm 12.00)\end{array}$ & $\begin{array}{l}\text { Laparoscopic } \\
\text { cholecystectomy }\end{array}$ & $\begin{array}{l}0.9 \% \text { saline } \\
250 \mathrm{~mL}\end{array}$ & $\begin{array}{l}5 \% \text { dextrose } \\
<108 \mathrm{~mL} \\
\left(100 \mathrm{~mL} \mathrm{~h}^{-1}\right)\end{array}$ & $\begin{array}{l}\text { Initiation upon } \\
\text { gallbladder removal, } \\
\text { continued until } \\
\text { surgery completion }\end{array}$ \\
\hline Patel et $a^{15}$ & $\begin{array}{l}162 \\
(75,87)\end{array}$ & $38 / 75,47 / 87$ & $\begin{array}{l}\text { I-2, female, } \\
45.5(43.0-47.9) \\
46.3(43.7-48.9)\end{array}$ & $\begin{array}{l}\text { Gynecologic, } \\
\text { urologic or } \\
\text { breast surgery }\end{array}$ & $\begin{array}{l}\text { Ringer's lactate } \\
250 \mathrm{~mL}\end{array}$ & $\begin{array}{l}5 \% \text { dextrose in } \\
\text { Ringer's lactate } \\
250 \mathrm{~mL}\end{array}$ & $\begin{array}{l}\text { Initiated with } \\
\text { surgical closure, } \\
>2 \text { hours }\end{array}$ \\
\hline Rao et $\mathrm{al}^{16}$ & $\begin{array}{l}115 \\
(59,56)\end{array}$ & $43 / 59,24 / 56$ & $\begin{array}{l}\mathrm{I}-2, \text { female and } \\
\text { male, } \\
43( \pm \mid 3) \\
44( \pm I I)\end{array}$ & $\begin{array}{l}\text { Laparoscopic } \\
\text { cholecystectomy }\end{array}$ & $\begin{array}{l}\text { Ringer's lactate } \\
\text { I,000 mL }\end{array}$ & $\begin{array}{l}5 \% \text { dextrose } \\
\mathrm{I}, 000 \mathrm{~mL}\end{array}$ & $\begin{array}{l}\text { After the end of } \\
\text { surgery in the } \\
\text { PACU, }>30 \text { minutes }\end{array}$ \\
\hline
\end{tabular}

Note: Ages are presented as mean $( \pm S D)$, or mean $(95 \% \mathrm{Cl})$.

Abbreviations: ASA, American Society of Anesthesiologists physical status classification; NA, not applicable; PACU, postanesthesia care unit; PONV, postoperative nausea and vomiting.

substantial (Figure 2). Three studies were considered high risk for allocation and four were considered high risk for the blinding of participants. However, these risks were unlikely to lead to further intervention during anesthesia or to have influenced the outcome assessment. The overall quality of the studies was found to be moderate to low using the GRADE approach.

\section{Incidence of PONV and requirement for anti-emetics}

Six studies ${ }^{10,11,13-16}$ reported the incidence of PONV. The results of our meta-analysis indicated that perioperative dextrose administration did not reduce the risk for PONV, compared with the control group (RR: $0.72,95 \%$ CI: 0.50-1.03) (Figure 3), and there was evidence of substantial heterogeneity $\left(I^{2}=71 \%\right)$. Two other studies ${ }^{15,16}$ also found that dextrose did not reduce the risk for vomiting (RR: 0.79, 95\% CI: 0.39-1.61) (Figure 4). However, perioperative dextrose reduced the requirement for anti-emetics, compared with the control group (RR: 0.60, 95\% CI: 0.44-0.83) (Figure 5). As with PONV, there was evidence of heterogeneity $\left(I^{2}=54 \%\right.$, moderate). The outcome of PONV was not affected by the inclusion of only high-quality studies ${ }^{11,14,15}$ (RR: $0.71,95 \%$ CI: $0.40-1.23)$ or the exclusion of two studies ${ }^{11,16}$ intervention of which was performed at postanesthesia care unit (RR: 0.76, 95\% CI: 0.42-1.39).

A subgroup analysis stratified by type of surgery demonstrated that perioperative dextrose could effectively prevent PONV associated with laparoscopic cholecystectomy. A total of 336 patients were included in three studies of laparoscopic cholecystectomy..$^{12,14,16}$ The results of two studies ${ }^{14,16}$ showed that dextrose significantly reduced the risk for PONV relative to the control group (Figure 3). All three studies reported the requirement for anti-emetics, which was also reduced in the dextrose group relative to the control group (Figure 5). 


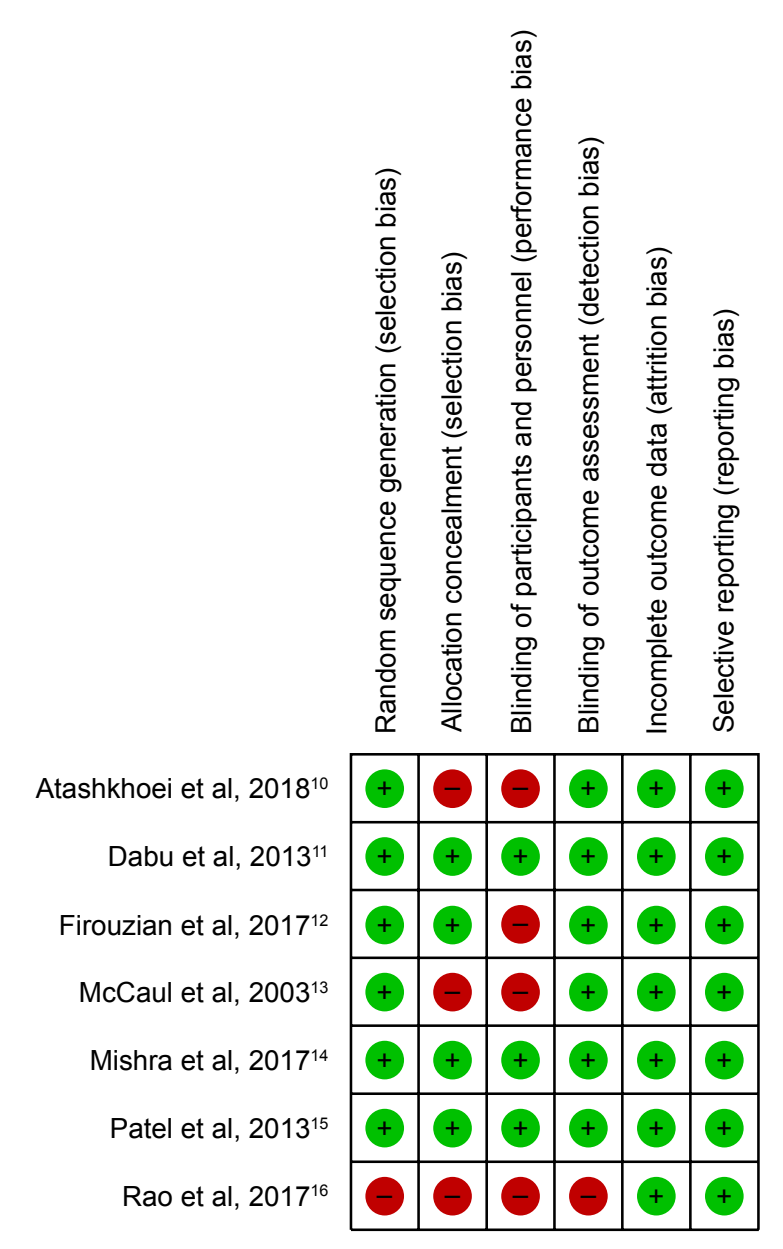

Figure 2 Risk of bias of original studies.

In contrast, perioperative dextrose did not improve the risk for PONV in studies of gynecologic, urologic, and/or breast surgery. ${ }^{10,11,13,15} \mathrm{~A}$ total of 365 patients were included in four such studies. Most underwent gynecologic surgery, while 20 patients in the dextrose group and 18 in the control group underwent urologic or breast surgery. In all four studies, dextrose did not reduce the risk for PONV relative to the control group (Figure 3). Similarly, three studies ${ }^{10,11,15}$ found no difference in the requirement for anti-emetics between the dextrose and control groups (Figure 5).

A subgroup analysis stratified by the volume of dextrose fluid demonstrated that the i.v. administration of $>1,000 \mathrm{~mL}$ reduced the risk for PONV. However, there was no significant difference between the dextrose fluid-volume subgroups $\left(I^{2}=0 \%\right)$ (Figure 6 ). Four studies ${ }^{10,12,15,16}$ reported the postoperative glucose levels $\left(\mathrm{mg} \mathrm{dL}^{-1}\right)$. In all but one heterogeneous study, the postoperative glucose levels were higher in the dextrose group relative to the control group (weighted mean difference $=20.83,95 \%$ CI: $3.77-37.88$ ) (Figure 7).

\section{Discussion}

In this meta-analysis, we found that the perioperative administration of dextrose did not seem to reduce the risk for PONV among patients undergoing surgery under general anesthesia. However, the results of this review should be considered cautiously. We do not condemn the general use of perioperative dextrose, as the analysis indicated a decrease in the requirement for anti-emetics in the dextrose group; rather, we find no evidence to support the routine use of perioperative dextrose as a prophylaxis against PONV in patients placed under general anesthesia. We particularly note that although most studies were heterogeneous, McCaul et $\mathrm{al}^{13}$ reported that the incidence of PONV was higher in the dextrose group than in the control group. Patients in that study received anesthesia for a duration of $<25$ minutes, which was shorter than in other studies, as well as a relatively large volume of dextrose. The duration of anesthesia has been identified as an independent risk factor for PONV development, ${ }^{17}$ and the administration of large amounts of dextrose during a short surgery with an otherwise low risk of PONV might only increase gastric emptying and gastric fullness consequent to hyperglycemia. It is well known that acute hyperglycemia slows gastric emptying both in healthy subjects and patients with diabetes mellitus. ${ }^{18-20}$

General anesthesia with volatile anesthetics is one of the most likely causes of PONV, consistent with our findings from all patients included in the meta-analysis. The type of surgery is also strongly believed to be a risk factor for PONV, ${ }^{17}$ and recent studies suggest laparoscopic and gynecologic surgery and cholecystectomy are independent risk factors for PONV. ${ }^{21-23}$ During laparoscopic surgery, $\mathrm{CO}_{2}$ pneumoperitoneum stimulates mechanoreceptors in the gastrointestinal tract, which leads to the release of serotonin and other neurotransmitters and increases the incidence of PONV.

Notably, the effect of perioperative dextrose on PONV varied according to the type of surgery. Here, perioperative dextrose effectively reduced the risk for PONV in three studies of laparoscopic cholecystectomy but not in four studies of other types of surgery. We cannot clearly explain this result, although as noted, i.v. dextrose might improve the risk for PONV via a mechanism related to hyperglycemia. In a previous study, the $\mathrm{pH}$ of gastric juice decreased significantly during laparoscopic cholecystectomy, ${ }^{24}$ and this phenomenon might induce gastric contraction. ${ }^{25}$ Hyperglycemia can reduce gastric acid secretion by inhibiting the vagal cholinergic pathways, ${ }^{7,8}$ and a recent previous study identified cholecystectomy as a cause of the severe duodenogastric reflux 


\begin{tabular}{|c|c|c|c|c|c|c|c|c|c|}
\hline $\begin{array}{l}\text { Study or } \\
\text { subgroup }\end{array}$ & $\begin{array}{l}\text { Dextrose } \\
\text { Events }\end{array}$ & Total & $\begin{array}{l}\text { Control } \\
\text { Events }\end{array}$ & Total & $\begin{array}{l}\text { Weight } \\
(\%)\end{array}$ & $\begin{array}{l}\text { Risk ratio } \mathrm{M}-\mathrm{H} \text {, } \\
\text { random, } 95 \% \mathrm{Cl}\end{array}$ & & \multicolumn{2}{|l|}{$\begin{array}{l}\text { Risk ratio } \mathrm{M}-\mathrm{H} \text {, } \\
\text { random, } 95 \% \mathrm{CI}\end{array}$} \\
\hline \multicolumn{10}{|c|}{ Laparoscopic cholecystectomy } \\
\hline Mishra A 2017 & 14 & 50 & 33 & 50 & 17.3 & $0.42(0.26-0.69)$ & & $\longrightarrow-$ & \\
\hline Rao V 2017 & 24 & 56 & 43 & 59 & 20.7 & $0.59(0.42-0.83)$ & & & \\
\hline Subtotal $(95 \% \mathrm{Cl})$ & & 106 & & 109 & 38.0 & $0.52(0.38-0.71)$ & & & \\
\hline Total events & 38 & & 76 & & & & & & \\
\hline \multirow{2}{*}{\multicolumn{10}{|c|}{$\begin{array}{l}\text { Heterogeneity: } \tau^{2}=0.01 ; \chi^{2}=1.19, d f=1(P=0.28) ; I^{2}=16 \% \\
\text { Test for overall effect: } Z=4.09(P<0.0001)\end{array}$}} \\
\hline \multicolumn{8}{|c|}{ Test for overall effect: $Z=4.09(P<0.0001)$} & & \\
\hline \multicolumn{10}{|c|}{ Gynecologic, urologic, or breast surgery } \\
\hline Atashkhoei S 2018 & 8 & 35 & 16 & 35 & 12.8 & $0.50(0.25-1.01)$ & & & \\
\hline Dabu B 2013 & 14 & 30 & 20 & 32 & 17.8 & $0.75(0.47-1.19)$ & & & \\
\hline McCaul C 2003 & 10 & 35 & 6 & 36 & 9.8 & $1.71(0.70-4.21)$ & & & \\
\hline Patel P 2013 & 47 & 87 & 38 & 75 & 21.7 & $1.07(0.79-1.43)$ & & & \\
\hline Subtotal $(95 \% \mathrm{Cl})$ & & 187 & & 178 & 62.0 & $0.89(0.60-1.31)$ & & & \\
\hline Total events & 79 & & 80 & & & & & & \\
\hline \multirow{2}{*}{\multicolumn{10}{|c|}{$\begin{array}{l}\text { Heterogeneity: } \tau^{2}=0.08 ; \chi^{2}=6.40, d f=3(P=0.09) ; l^{2}=53 \% \\
\text { Test for overall effect } Z=0.59(P=0.56)\end{array}$}} \\
\hline & & & & & & & & & \\
\hline Total $(95 \% \mathrm{Cl})$ & & 293 & & 287 & 100 & $0.72(0.50-1.03)$ & & & \\
\hline Total events & 117 & & 156 & & & & & & \\
\hline \multirow{2}{*}{\multicolumn{7}{|c|}{$\begin{array}{l}\text { Heterogeneity: } \tau^{2}=0.13 ; \chi^{2}=17.20, d f=5(P=0.004) ; I^{2}=71 \% \\
\text { Test for overall effect: } Z=1.82(P=0.07)\end{array}$}} & 1 & + & + \\
\hline & & & & & & & 0.02 & 10 & 50 \\
\hline \multicolumn{7}{|c|}{ Test for subgroup differences: $\chi^{2}=4.35, d f=1(P=0.04) ; I^{2}=77.0 \%$} & Favors (de & Favors (co & \\
\hline
\end{tabular}

Figure 3 Forest plot of the effects of perioperative intravenous dextrose administration on the risk for postoperative nausea and vomiting according to the type of surgery.

strongly associated with early gastric mucosal changes. ${ }^{26}$ The high osmotic pressure induced by i.v. dextrose also can reduce gastrointestinal wall contractions. ${ }^{11}$ Increased blood glucose levels may also increase the plasma level of cholecystokinin, a gastrointestinal peptide hormone that modulates anxiety and pain via its functions within the brain and consequently reduces pain and PONV. ${ }^{27}$ Although cholecystokinin levels have not been evaluated during cholecystectomy, altered concentrations of this hormone have been detected in patients after cholecystectomy. ${ }^{28}$

Furthermore, the effects of dextrose on the risk for PONV did not differ according to the administered fluid volume. However, the postoperative glucose levels were higher in the dextrose group relative to the control group, which may explain the reduced need for anti-emetics in the former group. In the four studies reporting postoperative glucose levels, however, the glucose

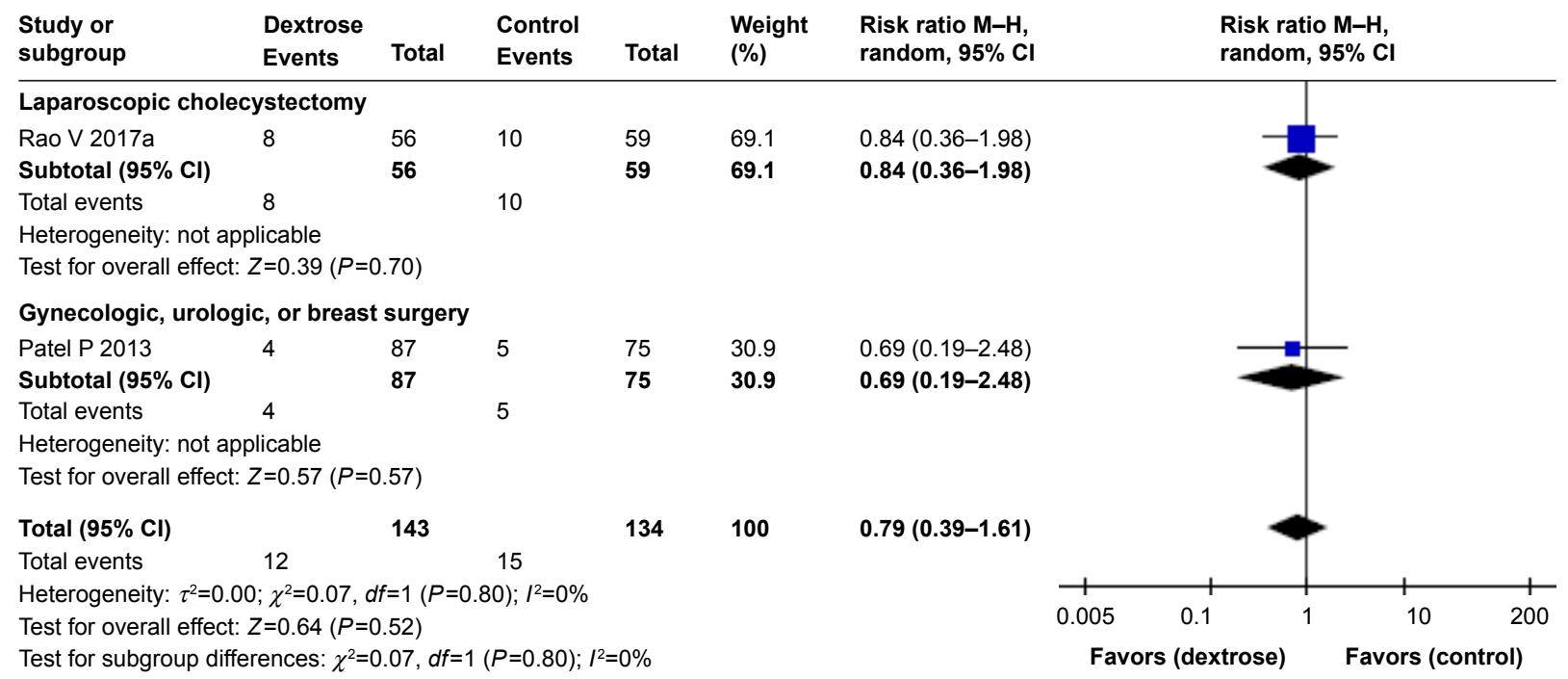

Figure 4 Forest plot of the effects of perioperative intravenous dextrose administration on the risk for postoperative vomiting according to the type of surgery. 


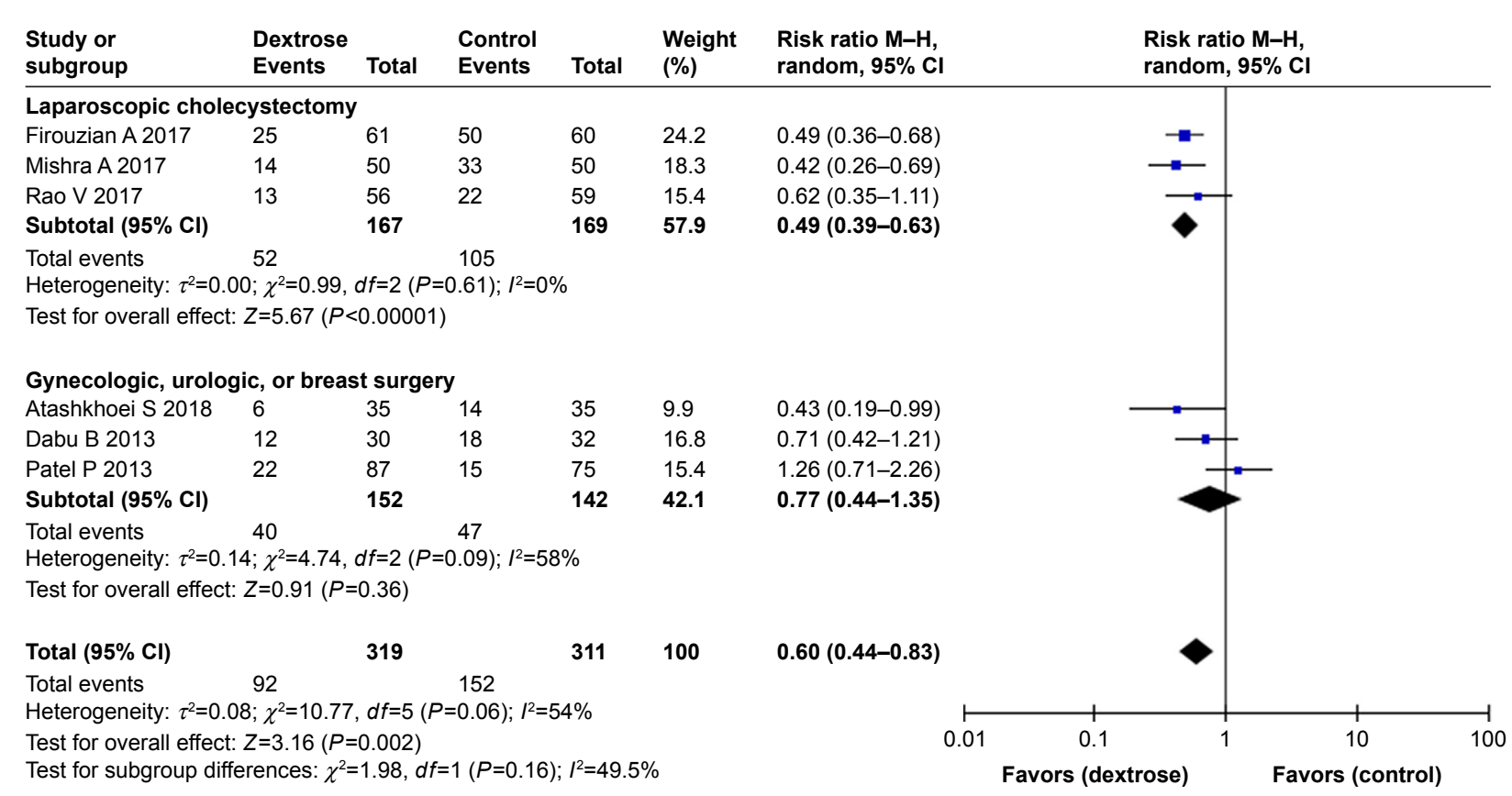

Figure 5 Forest plot of the effects of perioperative intravenous dextrose administration on the requirement for anti-emetic therapy according to the type of surgery.

levels also differed between the control groups. Perioperative dextrose was found to be effective at postoperative glucose levels $<100 \mathrm{mg} \mathrm{dL}^{-1}$, suggesting that hypoglycemia prevention might be more important than an elevated glucose level.
The present meta-analysis had some limitations that should be considered when interpreting the results. We included studies that varied with respect to the type of surgery and volume of administered dextrose fluid, which

\begin{tabular}{|c|c|c|c|c|c|c|c|c|c|}
\hline $\begin{array}{l}\text { Study or } \\
\text { subgroup }\end{array}$ & $\begin{array}{l}\text { Dextrose } \\
\text { Events }\end{array}$ & Total & $\begin{array}{l}\text { Control } \\
\text { Events }\end{array}$ & Total & $\begin{array}{l}\text { Weight } \\
\text { (\%) }\end{array}$ & $\begin{array}{l}\text { Risk ratio } \mathrm{M}-\mathrm{H} \text {, } \\
\text { random, } 95 \% \mathrm{Cl}\end{array}$ & & \multicolumn{2}{|l|}{$\begin{array}{l}\text { Risk ratio } \mathrm{M}-\mathrm{H} \text {, } \\
\text { random, } 95 \% \mathrm{Cl}\end{array}$} \\
\hline \multicolumn{10}{|l|}{$>1,000 \mathrm{~mL}$} \\
\hline Dabu B 2013 & 14 & 30 & 20 & 32 & 17.8 & $0.75(0.47-1.19)$ & & - & \\
\hline Rao V 2017 & 24 & 56 & 43 & 59 & 20.7 & $0.59(0.42-0.83)$ & & & \\
\hline Subtotal $(95 \% \mathrm{Cl})$ & & 86 & & 91 & 38.5 & $0.64(0.49-0.84)$ & & & \\
\hline Total events & 38 & & 63 & & & & & & \\
\hline \multicolumn{10}{|c|}{ Heterogeneity: $\tau^{2}=0.00 ; \chi^{2}=0.66, d f=1(P=0.42) ; I^{2}=0 \%$} \\
\hline \multicolumn{10}{|c|}{ Test for overall effect: $Z=3.19(P=0.001)$} \\
\hline \multicolumn{10}{|l|}{$500 \mathrm{~mL} \sim 1,000 \mathrm{~mL}$} \\
\hline Atashkhoei S 2018 & 8 & 35 & 16 & 35 & 12.8 & $0.50(0.26-1.01)$ & & & \\
\hline McCaul C 2003 & 10 & 35 & 6 & 36 & 9.8 & $1.71(0.70-4.21)$ & & & \\
\hline Subtotal $(95 \% \mathrm{Cl})$ & & 70 & & 71 & 22.5 & $0.90(0.27-3.00)$ & & & \\
\hline Total events & 18 & & 22 & & & & & & \\
\hline \multicolumn{10}{|c|}{ Heterogeneity: $\tau^{2}=0.59 ; \chi^{2}=4.47, d f=1(P=0.03) ; l^{2}=78 \%$} \\
\hline \multicolumn{10}{|c|}{ Test for overall effect: $Z=0.18(P=0.86)$} \\
\hline \multicolumn{10}{|l|}{$<500 \mathrm{~mL}$} \\
\hline Mishra A 2017 & 14 & 50 & 33 & 50 & 17.3 & $0.42(0.26-0.69)$ & & & \\
\hline Patel P 2013 & 47 & 87 & 38 & 75 & 21.7 & $1.07(0.79-1.43)$ & & & \\
\hline Subtotal $(95 \% \mathrm{Cl})$ & & 137 & & 125 & 39.0 & $0.69(0.28-1.71)$ & & & \\
\hline Total events & 61 & & 71 & & & & & & \\
\hline \multicolumn{10}{|c|}{ Heterogeneity: $\tau^{2}=0.39 ; \chi^{2}=10.31, d f=1(P=0.001) ; l^{2}=90 \%$} \\
\hline \multicolumn{10}{|c|}{ Test for overall effect: $Z=0.81(P=0.42)$} \\
\hline Total $(95 \% \mathrm{Cl})$ & & 293 & & 287 & 100 & $0.72(0.50-1.03)$ & & & \\
\hline Total events & 117 & & 156 & & & & & & \\
\hline \multirow{2}{*}{\multicolumn{7}{|c|}{$\begin{array}{l}\text { Heterogeneity: } \tau^{2}=0.13 ; \chi^{2}=17.20, d f=5(P=0.004) ; I^{2}=71 \% \\
\text { Test for overall effect: } Z=1.82(P=0.07)\end{array}$}} & & & \\
\hline Test for overall effect: $Z=1.82(P=0.07)$ & & & & & & & 0.02 & 10 & 50 \\
\hline Test for subgroup dif & es: $\chi^{2}=0.30$, & $d f=2(P$ & $0.86) ; l^{2}=0 \%$ & & & & Favors (de) & Favors (cc & \\
\hline
\end{tabular}

Figure 6 Forest plot of the effect of perioperative intravenous dextrose administration on the risk for postoperative nausea and vomiting stratified by the volume of dextrose fluid. 


\begin{tabular}{|c|c|c|c|c|c|c|c|c|c|c|c|c|}
\hline \multirow{2}{*}{$\begin{array}{l}\text { Study or } \\
\text { subgroup } \\
\text { Atashkhoei S } 2018\end{array}$} & \multicolumn{3}{|c|}{ Dextrose } & $\begin{array}{l}\text { Control } \\
\text { Mean }\end{array}$ & SD & Total & $\begin{array}{l}\text { Weight } \\
(\%)\end{array}$ & \multicolumn{2}{|l|}{$\begin{array}{l}\text { Mean difference IV, } \\
\text { random, } 95 \% \mathrm{CI}\end{array}$} & \multicolumn{2}{|c|}{$\begin{array}{l}\text { Mean difference IV, } \\
\text { random, } 95 \% \mathrm{Cl}\end{array}$} & \\
\hline & 93.4 & 1.38 & 35 & 86.51 & 1.24 & 35 & 35.3 & $6.89(6.28-7.50)$ & & & 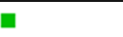 & \\
\hline Firouzian A 2017 & 142.06 & 25.85 & 61 & 115.09 & 12.76 & 60 & 33.2 & $26.97(19.72-34.22)$ & & & - & \\
\hline Patel P 2013 & 137 & 42.228 & 87 & 107 & 21.7317 & 75 & 31.4 & $30.00(19.85-40.15)$ & & & - 븜 & \\
\hline Rao V 2017 & 282 & 32 & 56 & 92 & 8 & 59 & 0.0 & 190.00 (181.37-198.63) & & & & \\
\hline Total $(95 \% \mathrm{Cl})$ & & & 183 & & & 170 & 100 & $20.83(3.77-37.88)$ & & & & \\
\hline \multicolumn{9}{|c|}{$\begin{array}{l}\text { Heterogeneity: } \tau^{2}=214.05 ; \chi^{2}=48.90, d f=2(P<0.00001) ; l^{2}=96 \% \\
\text { Test for overall effect: } Z=2.39(P=0.02)\end{array}$} & -100 & -50 & 50 & 100 \\
\hline & & & & & & & & & Low le & (dextrose) & Low leve & ntrol) \\
\hline
\end{tabular}

Figure 7 Forest plot of the effects of perioperative intravenous dextrose administration on postoperative glucose levels $\left(\mathrm{mg} \mathrm{dL}^{-1}\right)$.

may account for some of the heterogeneity observed in our analytical results. We could reduce heterogeneity in the subgroup analysis of studies only involving laparoscopic cholecystectomy. However, further studies are needed in this subgroup in that the incidence of PONV was reported only in two studies. Second, because the studies included in this meta-analysis were mostly limited to laparoscopic cholecystectomy and gynecologic surgeries, the results of this meta-analysis cannot be generalized to other surgeries. Further studies with larger numbers of patients and more varied types of surgeries are warranted to clarify the beneficial effects of perioperative i.v. dextrose on PONV in patients under general anesthesia.

\section{Conclusion}

Perioperative i.v. dextrose did not reduce the incidence of PONV but did reduce the need for anti-emetics after general anesthesia. However, dextrose did reduce the incidence of PONV among patients who underwent laparoscopic cholecystectomy. More studies are needed to determine the benefit of perioperative dextrose as a preventive measure against PONV.

\section{Author contributions}

All authors contributed toward data analysis, drafting, and critically revising the paper, and agree to be accountable for all aspects of the work.

\section{Disclosure}

The authors report no conflicts of interest in this work.

\section{References}

1. Le TP, Gan TJ. Update on the management of postoperative nausea and vomiting and postdischarge nausea and vomiting in ambulatory surgery. Anesthesiol Clin. 2010;28(2):225-249.

2. Macario A, Weinger M, Carney S, Kim A. Which clinical anesthesia outcomes are important to avoid? The perspective of patients. Anesth Analg. 1999;89(3):652-658.

3. Kranke P, Eberhart LH. Possibilities and limitations in the pharmacological management of postoperative nausea and vomiting. Eur $J$ Anaesthesiol. 2011;28(11):758-765.
4. Sada F, Krasniqi A, Hamza A, Gecaj-Gashi A, Bicaj B, Kavaja F. A randomized trial of preoperative oral carbohydrates in abdominal surgery. BMC Anesthesiol. 2014;14:93.

5. Lauwick SM, Kaba A, Maweja S, Hamoir EE, Joris JL. Effects of oral preoperative carbohydrate on early postoperative outcome after thyroidectomy. Acta Anaesthesiol Belg. 2009;60(2):67-73.

6. Magner JJ, McCaul C, Carton E, Gardiner J, Buggy D. Effect of intraoperative intravenous crystalloid infusion on postoperative nausea and vomiting after gynaecological laparoscopy: comparison of 30 and $10 \mathrm{~mL} \mathrm{~kg} \mathrm{(-1).} \mathrm{Br} \mathrm{J} \mathrm{Anaesth.} \mathrm{2004;93(3):381-385.}$

7. Loud FB, Holst JJ, Rehfeld JF, Christiansen J. Inhibition of gastric acid secretion in humans by glucagon during euglycemia, hyperglycemia, and hypoglycemia. Dig Dis Sci. 1988;33(5):530-534.

8. Lam WF, Masclee AA, de Boer SY, Lamers CB. Hyperglycaemia reduces gastrin-stimulated gastric acid secretion in humans. Eur J Clin Invest. 1998;28(10):826-830.

9. Julian PT, Higgins SG. Cochrane Handbook for Systematic Reviews of Interventions. 5.1 edn. Chichester, West Sussex, England: John Wiley \& Sons; 2011.

10. Atashkhoei S, Naghipour B, Marandi PH, Dehghani A, Pourfathi H. Effect of Intraoperative Dextrose Infusion for Prevention of Postoperative Nausea and Vomiting in Diagnostic Gynecologic Laparoscopy. Crescent Journal of Medical and Biological Sciences. 2018; 5(1):45-49.

11. Dabu-Bondoc S, Vadivelu N, Shimono C, et al. Intravenous dextrose administration reduces postoperative antiemetic rescue treatment requirements and postanesthesia care unit length of stay. Anesth Analg. 2013;117(3):591-596.

12. Firouzian A, Kiasari AZ, Godazandeh G, et al. The effect of intravenous dextrose administration for prevention of post-operative nausea and vomiting after laparoscopic cholecystectomy: A double-blind, randomised controlled trial. Indian J Anaesth. 2017;61(10):803-810.

13. McCaul C, Moran C, O'Cronin D, et al. Intravenous fluid loading with or without supplementary dextrose does not prevent nausea, vomiting and pain after laparoscopy. Can J Anaesth. 2003;50(5):440-444.

14. Mishra A, Pandey RK, Sharma A, et al. Is perioperative administration of $5 \%$ dextrose effective in reducing the incidence of PONV in laparoscopic cholecystectomy? A randomized control trial. J Clin Anesth. 2017;40:7-10.

15. Patel P, Meineke MN, Rasmussen T, et al. The relationship of intravenous dextrose administration during emergence from anesthesia to postoperative nausea and vomiting: a randomized controlled trial. Anesth Analg. 2013;117(1):34-42.

16. Rao V, Bala I, Jain D, Bharti N. Effect of intravenous dextrose administration on postoperative nausea and vomiting in patients undergoing laparoscopic cholecystectomy: a randomised controlled trial. Eur $J$ Anaesthesiol. 2017;34(10):705-707.

17. Gan TJ, Diemunsch P, Habib AS, et al. Consensus guidelines for the management of postoperative nausea and vomiting. Anesth Analg. 2014; 118(1):85-113.

18. Macgregor IL, Gueller R, Watts HD, Meyer JH. The effect of acute hyperglycemia on gastric emptying in man. Gastroenterology. 1976;70(2): 190-196. 
19. Fraser RJ, Horowitz M, Maddox AF, Harding PE, Chatterton BE, Dent J. Hyperglycaemia slows gastric emptying in type 1 (insulindependent) diabetes mellitus. Diabetologia. 1990;33(11):675-680.

20. Jones KL, Berry M, Kong MF, Kwiatek MA, Samsom M, Horowitz M. Hyperglycemia attenuates the gastrokinetic effect of erythromycin and affects the perception of postprandial hunger in normal subjects. Diabetes Care. 1999;22(2):339-344.

21. Apfel CC, Kranke P, Eberhart LH. Comparison of surgical site and patient's history with a simplified risk score for the prediction of postoperative nausea and vomiting. Anaesthesia. 2004;59(11) 1078-1082.

22. Sinclair DR, Chung F, Mezei G. Can postoperative nausea and vomiting be predicted? Anesthesiology. 1999;91(1):109-118.

23. Gan TJ. Risk factors for postoperative nausea and vomiting. Anesth Analg. 2006;102(6):1884-1898.
24. Baraka A, Jabbour-Khoury S, Karam V, et al. Correlation of the endtidal PCO2 during laparoscopic surgery with the $\mathrm{pH}$ of the gastric juice. JSLS. 1998;2(2):163-167.

25. Agarwal A, Dhiraaj S, Tandon M, Singh PK, Singh U, Pawar S. Evaluation of capsaicin ointment at the Korean hand acupressure point K-D2 for prevention of postoperative nausea and vomiting. Anaesthesia. 2005;60(12):1185-1188.

26. Mercan E, Duman U, Tihan D, Dilektasli E, Senol K. Cholecystectomy and duodenogastric reflux: interacting effects over the gastric mucosa. Springerplus. 2016;5(1):1970.

27. Ljungqvist $\mathrm{O}$, Nygren $\mathrm{J}$, Thorell A. Insulin resistance and elective surgery. Surgery. 2000;128(5):757-760.

28. Mcdonnell CO, Bailey I, Stumpf T, Walsh TN, Johnson CD. The effect of cholecystectomy on plasma cholecystokinin. Am J Gastroenterol. 2002;97(9):2189-2192.

\section{Publish your work in this journal}

Therapeutics and Clinical Risk Management is an international, peerreviewed journal of clinical therapeutics and risk management, focusing on concise rapid reporting of clinical studies in all therapeutic areas, outcomes, safety, and programs for the effective, safe, and sustained use of medicines. This journal is indexed on PubMed Central, CAS,

\section{Dovepress}

EMBase, Scopus and the Elsevier Bibliographic databases. The manuscript management system is completely online and includes a very quick and fair peer-review system, which is all easy to use. Visit http://www.dovepress.com/testimonials.php to read real quotes from published authors.

Submit your manuscript here: http://www.dovepress.com/therapeutics-and-clinical-risk-management-journal 